\title{
Current Status of the Use of Cloud Computing in SMEs in the City of Latacunga, Ecuador
}

\author{
Gabriela Cajamarca-Palomo ${ }^{1}$, Mauricio Quisimalin-Santamaría1, Patricio Medina-Chicaiza ${ }^{2 *}$ \\ ${ }^{1}$ Facultad de Ciencias Administrativas, Universidad Técnica de Ambato, Ambato, Ecuador \\ ${ }^{2}$ Facultad de Ciencias Administrativas, Universidad Técnica de Ambato, Pontificia Universidad Católica del Ecuador, \\ Ambato, Ecuador \\ Email: *ricardopmedina@uta.edu.ec
}

How to cite this paper: CajamarcaPalomo, G., Quisimalin-Santamaría, M. and Medina-Chicaiza, P. (2019) Current Status of the Use of Cloud Computing in SMEs in the City of Latacunga, Ecuador. Open Journal of Business and Management, 7, 633 649.

https://doi.org/10.4236/ojbm.2019.72043

Received: March 1, 2019

Accepted: April 1, 2019

Published: April 4, 2019

Copyright (c) 2019 by author(s) and Scientific Research Publishing Inc. This work is licensed under the Creative Commons Attribution International License (CC BY 4.0).

http://creativecommons.org/licenses/by/4.0/

\begin{abstract}
This document is the result of a descriptive research on and analysis of hierarchical conglomerates. Its purpose is to investigate the current state of Cloud Computing (CC) use in small and medium enterprises (SMEs) in the city of Latacunga, Ecuador. The construction of the instrument was based on the planning, application, analysis and validation of a questionnaire using Kuder Richarson 20 (KR20), which resulted in 0.81. The SPSS and Nvivo software were used with the participation of 43 SMEs from productive sectors, such as agriculture, manufacturing, commerce and service. The questionnaire was made up of 17 questions, grouped in two parts for the Department of Information Technology (IT) and administrative personnel. The results show that $65.1 \%$ know about CC, however, a low applicability is evident. A set of more relevant questions determines the decision making of the use of Cloud Computing in SMEs.
\end{abstract}

\section{Keywords}

Cloud Computing, Small Business, Security, Information

Technology, Infrastructure as a Service, Platform as a Service,

Software as a Service

\section{Introduction}

Small and medium enterprises (SMEs) have an important economic role in different countries. Some authors [1] [2] [3] mention that SMEs represent 79\% of businesses worldwide, 95\% in Latin America, and 99\% in Ecuador. SMEs in Ecuador are established as the main source of direct and indirect work, and their participation in the development of the country is transcendental. According to 
data from the National Institute of Statistics and Census ${ }^{1}$ (INEC), 8447 companies were registered in Ecuador, divided into 19 productive activities, of which $90.5 \%$ are SMEs. This information is compiled by the Board of Directors of Companies from records generated by the Internal Revenue Service ${ }^{2}$ (SRI) and the Social Security Institute ${ }^{3}$ (IEES) from a sectoral and territorial perspective. According to [4], SMEs are defined by sales volume, social capital, number of employees, and their level of production; which are received in Ecuador and are regulated by the law of company and tax regime.

SMEs play an important role in the country's economy, because apart from contributing to the creation of jobs, they also promote the economic recovery of certain regions and foster technological progress. Their capacity depends fundamentally on the ability of the manager/owner to invest in intangible products, technological products and their capacity for flexible innovation.

Authors [5] [6] [7] agree that one of the most important technological developments of recent years is Cloud Computing. The potential benefits of these technologies include the benefits of an operational nature to implement the automation of routine procedures through a broad network that acts on demand through a group of virtualized resources and configured among themselves and the quick provisioning of information to any part of the world.

In this sense, other authors [8] [9] add that Cloud Computing works through the Internet, through a subscription for payment for service use. It manages three relevant models among its services, which are: IaaS (Infrastructure as a service), which is considered as the traditional hosting service in a data center, PaaS (Platform as a service), which includes Infrastructure as a service plus additional ones, and SaaS (Software as a service), where applications are given by a provider. In relation to the above, Cloud Computing offers different functionalities, ready to meet the business need, which can be used in administrative processes that the company has, such as accounting, billing, human talent, among others.

From this approach, according to authors [8] [10] [11], the importance of the use of CC in public and private companies is shown, because the incessant technical innovation allows companies to have data storage, backup copies, access to information from different computers, among others. With this, decision making is carried out in a timely manner, when information is required unexpectedly. In this sense, according to [12] in its article entitled Incipient "Adoption of Cloud" 4 , it is detailed that from $100 \%$ of Ecuadorian companies, only $17 \%$ make use of this service among large companies and SMEs, which is considerably below compared to neighboring countries such as Colombia, Peru and Chile, with $58 \%$. It is assumed that a large part of SMEs are unaware of the benefits offered by the implementation of this service, as well as of cases of application in the

\footnotetext{
${ }^{1}$ Nacional de Estadísticas y Censos.

${ }^{2}$ Servicio de Rentas Internas.

${ }^{3}$ Seguridad Social.

${ }^{4}$ Incipiente adopción de Cloud.
} 
Ecuadorian environment.

Likewise, the factors related to the use of Cloud Computing in Ecuador have been approached from different authors' perspectives [13] [14] [15] where methodologies and results of the use of ICT in the business area are generally evident. However no study provides information on its application, as well as the use of Cloud Computing in the productive sectors such as: agriculture, manufacturing, service and commerce in the study city, which allows businessmen to make decisions for the implementation of Cloud Computing. With the aforementioned background, the objective of this study is to present the current state of the use of Cloud Computing in SMEs in the city of Latacunga-Ecuador.

In addition to this, the contributions of this study are mainly based on the adaptability of the cloud computing service to the different requirements and needs of the companies; they also involve economic aspects, because they allow a reduction in their costs, when using this service. Therefore, managers or owners of companies have access to personalized information for each one, which can share it internally and access it from any connection point.

The article is organized as follows, as the first point is the definition of SMEs with an international context, showing their classification and their sectors in Ecuador, as well as the use of ICT and the current state of CC in the country. As a second point, the methodology applied for this research is detailed, as well as the instruments for data collection and validation. From this, the results are manifested and finally, the conclusions of the investigation.

\section{Theoretical Framework}

\subsection{Small and Medium Enterprises (SMEs)}

The definition of SMEs arises at the end of the seventies as a result of the economic failure of 500 large companies in the United States [16]. In addition, SMEs are productive or service entities which are formally constituted and managed independently [13] [14] [15] [17] [18]. It is important to clarify that there are different definitions and classifications of SMEs according to each country [1] [19] [20]. To this, the proposal of [21] is assumed, who mention that SMEs are considered among other factors, according to the number of workers and the amount of income they produce.

In the same sense, Table 1 shows the classification by size of SMEs in accordance

Table 1. Criteria for the classification of SMEs.

\begin{tabular}{cccc}
\hline Classification & Number of employees & Annual sales (USD) & Total assets (USD) \\
\hline Micro & 1 to 9 & $\leq 100,000$ & $\leq 100,000$ \\
Small & 10 to 49 & 100,001 to $1,000,000$ & 100,001 to 750,000 \\
Medium & 50 to 99 & $1,000,001$ to $5,000,000$ & 750,001 to $4,000,000$ \\
Big & 200 or more & More than $5,000,000$ & More to $4,000,000$ \\
\hline
\end{tabular}

Source: Andean Community of the United Nations [23]. 
with the plan presented by the Andean Community of the United Nations $\left(\mathrm{CAN}^{5}\right)$, adopted in this investigation. According to [22], in Ecuador economic growth has been on the rise, thanks to the fact that SMEs contribute to the improvement of the quality of life of Ecuadorians through the generation of employment and family support, motivating governments to show interest in the implementation of policies that promote the creation and sustenance of these companies.

It is important to point out that in Ecuador, in addition, the file called the International Standard Industrial Classification $\left(\mathrm{CIUU}^{6}\right)$, established by the United Nations, which catalogs the activities in a series of categories and subcategories, is used for the classification of SMEs in sectors.

Table 2 shows the sectors that operate in the country where the agricultural, cattle raising, forestry and fishing sectors reflect a percentage of $40 \%$; followed by trade with $9 \%$ and public administration and defense with $7 \%$, considering that they are also managed by their own policies. It is important to mention that this achievement is also due to the support of private financial entities such as banks, cooperatives, mutualists, financial companies and credit cards which, through satisfactory financing, promote the development of SMEs.

Table 2. Distribution of SMEs in Ecuador by sector.

\begin{tabular}{|c|c|}
\hline Economic sectors & Number of SMEs \\
\hline Agriculture, cattle raising, forestry and fishing & 26,282 \\
\hline Mining and quarrying & 4075 \\
\hline Manufacturing industries & 2381 \\
\hline Electricity, gas, steam and air conditioning supply & 1055 \\
\hline Water distribution; sewerage, waste and sanitation & 672 \\
\hline Building & 1730 \\
\hline Trade, automotive repair and motorcycles & 5940 \\
\hline Transportation and storage & 2010 \\
\hline Accommodation and meal service activities & 3010 \\
\hline Information and communication & 1342 \\
\hline Financial and insurance activities & 277 \\
\hline Real estate activities & 1304 \\
\hline Professional, scientific and technical activities & 4596 \\
\hline Administrative and support services activities & 334 \\
\hline Public administration and defense, social security & 5729 \\
\hline Teaching & 75 \\
\hline Activities for human health care and social assistance & 117 \\
\hline Arts, training and recreation & 3791 \\
\hline
\end{tabular}

Source: adapted from [24], from INEC (2015).

${ }^{5}$ Comunidad Andina de las Naciones Unidas.

${ }^{6}$ Clasificación Industrial Internacional Uniforme. 


\subsection{Information and Communication Technologies (ICT) in Companies in Ecuador}

The use of technologies in companies brings competitive strategies to national and international levels, along with the economic growth and profitability of the country. This, in turn, induces interest to build new explanatory theories from a perspective of competitive advantage in terms of the extent of use of ICT in the key activities of the company at the time of storage, processing and acquisition of information [25] [26] [27]. Therefore, the need to integrate ICT to the business model is prevailing for competition on equal terms.

Given this situation, [28] $\mathrm{MINTEL}^{7}$, indicates that a project has been implemented in Ecuador to train micro enterprises in basic uses of business ICT through a National Infocenter Network $^{8}$ with the objective of increasing the use of specific ICTs in SMEs according to their sector, industry and economic activity. This project is framed in Guideline 11.3 of the National Plan for Good Living ${ }^{9}$ 2013-2017 approved by the National Planning Council ${ }^{10}$ [29] in order to strengthen ICT use capabilities in SMEs. This is why such an impulse is offered in the country for the use of this technology.

Regarding technological investment for universities, on the one hand, it is an instantaneous moment to adopt the SMEs of the $11 \%$, while large companies evidence a decrease in investment. This variance could be due to the fact that SMEs participate actively and even dominantly in the country (Figure 1).

Figure 2 shows that the manufacturing sector has the greatest investment in ICT use, reaching $48.8 \%$. Also, commerce has had a considerable growth along with services; mining presents very low values, which makes their little investment in ICT evident. These results reflect that investment in ICT varies in relation to the activity to which SMEs are dedicated. It should be noted that the research study does not show whether the investment was in hardware or software.

Regarding the use of provincial ICT according to INEC data, the provinces that are most linked to the use of technology are Galapagos with $68.4 \%$ and the

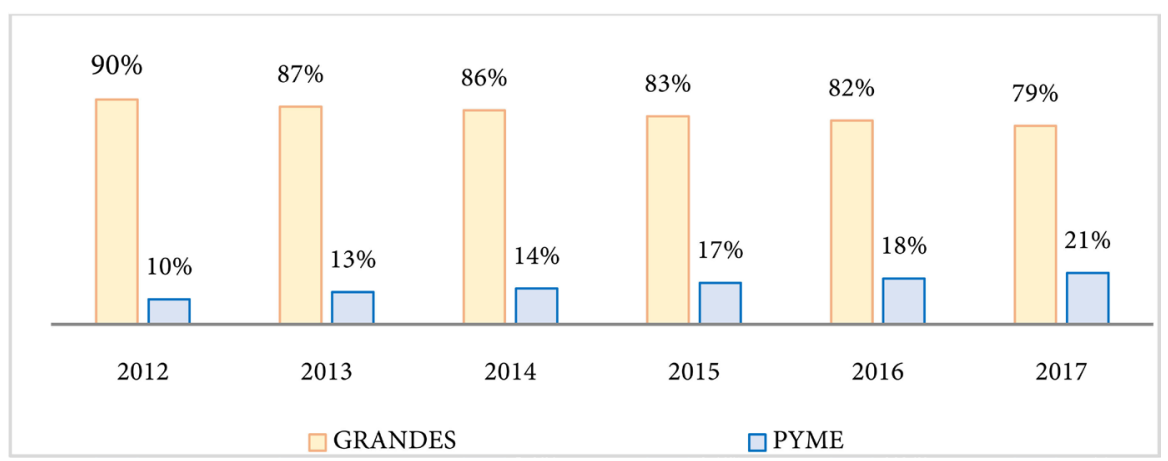

Source: adapted from [28].

Figure 1. Investment in ICT according to the size of the company.

${ }^{7}$ Ministerio de Telecomunicaciones y de la Sociedad de Información.

${ }^{8}$ Red Nacional de Infocentros.

${ }^{9}$ Plan Nacional del Buen Vivir.

${ }^{10}$ Consejo Nacional de Planificación. 


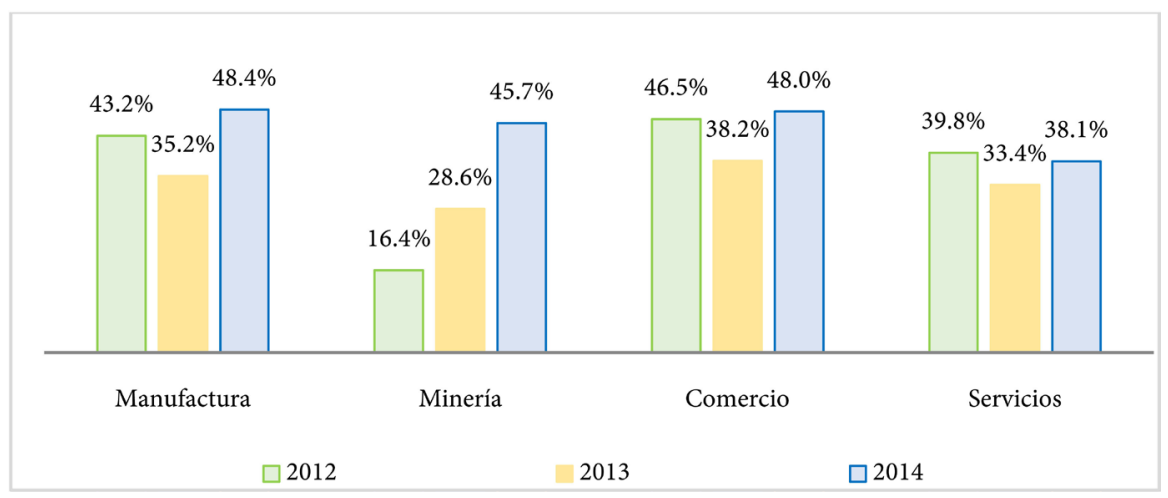

Source: adapted from [30].

Figure 2. Investment in ICT by sector USD.

province under study, Cotopaxi, where its use reaches $50.4 \%$, thus showing that growth and adaptation to this resource is rapid, with a slight difference of $18 \%$.

\subsection{Cloud Computing}

Some authors [31] [32] [33] indicate that Cloud Computing has been contextualized in different ways. They also establish that the most common definition is adopted by the National Institute of Standards and Technology (NIST ${ }^{11}$ ), which refers to Cloud Computing as computer groups, features and models. References [34] [35] [36] state that Cloud Computing integrates the stability, scalability and delivery of a service. In addition, [37] [38] point out that it is a business application on a website, through which organizations today have opted to manage their information. Therefore, Cloud Computing allows users to access data resources from any geographical location through the Internet.

Cloud Computing offers three main models [39]: Software as a Service (SaaS), where customers can access applications that are hosted by the service provider [40]; platform as a service (PaaS), which is more oriented towards software developers in working groups for programmers [41]; and infrastructure as a service (IaaS), where users make use of virtual servers with characteristics that they choose [42]. In this sense, it should be noted that each of them, although belonging to the same service, manages its own benefits and costs.

The general idea of Cloud Computing lies in its online expansion to share, process and synchronize data from a perspective of advantages in terms of installation, configuration, updating, maintenance, costs and others. However, [43] [44] [45] describe that, despite the advantages in the use of CC, its adoption is not so fast and widespread due to difficulties such as: security and privacy, interception or manipulation of data by third parties, loss of information, direct dependence on a provider, connectivity to the network, among others. This is why it is necessary to give information about CC use so as not to generalize fortuitous cases of management.

While the advantages and disadvantages of the use of CC differ, the notion of

\footnotetext{
${ }^{11}$ Nacional de Estándares y Tecnología.
} 
service brings significant impacts to the economy because of the rapid development and the changing and competitive environments in which companies operate [46] [47]. Therefore, it is necessary to have a fast coupling and adjustment to the commercial models that come up. In addition, the authors [48] [49] [50] state that the level of maturity varies based on the model presented, such is the case of SaaS, which is in the stage of growth, while models such as IaaS and PaaS are at a level of initial maturity in terms of use in SMEs.

Reference [51] indicate that companies must be aware of the digital transformation to which they are exposed and also be prepared to adapt to it. It is evident then that Ecuador cannot be the exception, that is why [52] publishes the White Paper on Digital Territories in Ecuador ${ }^{12}$, where information about the adoption of cloud computing technologies is revealed. In this document, the information coincides with the magazine Computer World in terms used to refer to the adoption of Cloud Computing in Ecuador as incipient, since $42 \%$ of SMEs surveyed, only $25 \%$ use Cloud Computing and $22 \%$ do not. This is due to the fact that the organizations express their perception of security risk, but that in turn the reduction of infrastructure costs is their main motivation for the acquisition of this service.

In addition, Ecuador highlights the need to implement five axes to strengthen the Information and Knowledge Society, which highlights the importance of one of its axes linked to the digital economy and emerging technologies in order to improve the productivity and competitiveness of the productive sectors of the country and the analytical services of handling large volumes of data, such as Cloud Computing. This highlights the importance of having studies on these elements.

\section{Methodology}

In this study, regulatory sites of the Ecuadorian business regulations and documents in Spanish and English were reviewed from online journals of Scopus, Science Direct, Web of Science and ProQuest published in the last 10 years, the studies were identified with key words, among which stand out: IT in the company, cloud computing, cloud computing services and Cloud Computing in SMEs, where 498 results were found in relation to the subject. The criteria of selectivity was based on: advantages and disadvantages of Cloud Computing, ICT applications in Ecuador and Cloud Computing use survey models, which contributed to the study topic.

Similarly, the recommendations for the construction of the theoretical, statistical and explanatory framework of the object of study were accepted [53] [54]. The investigation started from the analysis of empirical studies in a systematic way of the selected sources [6] [55] [56].

For the qualitative study, an exploratory analysis was carried out using hierarchical conglomerates, which according to [57] [58] [59] consists of determining the dimensions established in groups, which allowed to identify how these variables in-

\footnotetext{
${ }^{12}$ Libro Blanco de Territorios Digitales en Ecuador.
} 
fluence the use of Cloud Computing of SMEs in the city of Latacunga-Ecuador, through intergroup links and chi-square measurement counts. In addition to better understanding, a dendrogram is established that clearly reflects the groups conformed by the nominal variables established in the questionnaire questions.

On the other hand, the exploration was carried out through a questionnaire, divided into two parts. The participation profiles to answer the items in the first part were addressed to staff with administrative positions and access to a computer, without requirement of deep knowledge of Cloud Computing. In the second instance, the survey was explicitly directed to the IT department. Likewise, the technique of the personal pilot interview was used with a questionnaire of five questions that lasted an average of 15 minutes per person. This served as input for the design of a questionnaire of 17 questions and application of the questionnaire. The information was collected through Google Drive, with an online survey sent by email to the companies under study, in which information relevant to this research was collected. The questions were of dichotomous type that allowed to obtain precise information, in order to justify the answers, through a statistical analysis, Kuder Richarson20 (KR20) was used, for the validation of the instrument.

Formula:

$$
K R 20=\left(\frac{n}{n-1}\right)\left(\frac{V t-\sum p q}{V t}\right)
$$

where:

$K R 20=$ Reliability Coefficient (Kuder Richarson)

$n=$ number of items that the instrument contains

$V t=$ Total variance of the test

$p=$ positive probability

$q=$ Negative probability $(1-\mathrm{p})$

After applying the formula a level of reliability according to data was obtained:

$$
\mathrm{KR} 20=0.81
$$

The population under study of this research are the SMEs of the agricultural (A), manufacturing $(\mathrm{C})$, commerce $(\mathrm{G})$ and services $(\mathrm{N})$ sectors of the city of Latacunga, since they are companies of greater number within the province, that use or are benefited by the Cloud Computing technology service in its different strategies. The report was initially developed with a population of 76 SMEs, however, only 43 SMEs from the city under study were involved, due to the fact that not all SMEs were still active, some maintain certain data disclosure restriction policies, among other reasons. These SMEs contained a range of existence in the market, going from 5 years to 21 years.

\section{Results}

The NVivo software was applied for the findings, which allowed analyzing qua- 
litative data in relation to most used clouds in SMEs. As for the qualitative analysis, data was processed in the SPSS software (Statistical Package for the Social Sciences), for the obtaining of descriptive results and the realization of hierarchical conglomerates.

\section{Main results}

Table 3 shows the sectors of the SMEs under study versus the range of years to which they belong expressed in percentages.

As shown in the table above, most of the companies corresponding to $32.6 \%$ are in a range of between 6 and 10 years in the market, most of them dedicated to commercial activities. It is also observed that $27.9 \%$ are have 5 years and that most of them carry out agricultural activities.

The main Internet uses of the 43 companies surveyed show that: a) $81.4 \%$ use the Internet for activities such as social networks; while b) $65.1 \%$ use it for communication through e-mail, since the respondents stated that it is an effective means of communication inside and outside the company, in addition to being an economic and ecological mean, which saves resources; and c) $44 \%$ respond to the payment of basic services.

In addition, in terms of the departments that make the most use of computer programs for the execution of their tasks there are management, accounting, information technologies and human talent, which have more access to the tool for the execution of their tasks with $97.7 \%, 81.4 \%, 65.1 \%$ and $53.5 \%$ respectively. Departments such as purchasing, marketing, finance, risk management and others, do not operate through this resource. In relation to security, the results show that $69.8 \%$ claim to use user ID and password to access their computer; $65.1 \%$ say they make backup copies of their digital documents in flash memory and compact discs; and $51.2 \%$ of SMEs maintain security policies; while an average of $38.1 \%$ affirm that they do not use any of these three means of security. These results reflect the use of ICT within SMEs; but not the benefits of including Cloud Computing.

With respect to ICT staff training, $23.3 \%$ state that they receive training at least twice a year, however, a high percentage, $76.7 \%$, indicate that they have no training in this regard, which is obvious lack of foray into specific issues such as

Table 3. Sector versus years of existence in the SME market.

\begin{tabular}{cccccc}
\hline $\begin{array}{c}\text { Year range in which the com- } \\
\text { pany is found }\end{array}$ & $\begin{array}{c}\text { Agriculture, cattle } \\
\text { raising and fishing }\end{array}$ & Manufacturing & Commerce & Services & Total \\
\hline Up to 5 (years) & $9.3 \%$ & $7.0 \%$ & $7.0 \%$ & $4.7 \%$ & $27.9 \%$ \\
Between 6 and 10 (years) & $9.3 \%$ & $7.0 \%$ & $16.3 \%$ & $0,0 \%$ & $32.6 \%$ \\
Between 11 and 15 (years) & $2.3 \%$ & $0,0 \%$ & $14.0 \%$ & $0,0 \%$ & $16.3 \%$ \\
Between 16 and 20 (years) & $0,0 \%$ & $2.3 \%$ & $2.3 \%$ & $0,0 \%$ & $4.7 \%$ \\
From 21 (years) & $7.0 \%$ & $7.0 \%$ & $2.3 \%$ & $2.3 \%$ & $18.6 \%$ \\
Total & $27.9 \%$ & $23.3 \%$ & $41.9 \%$ & $7.0 \%$ & $100.0 \%$ \\
\hline
\end{tabular}

Source: own elaboration. 
services and use of Cloud Computing. On the other hand, $60.5 \%$ of the companies said they had personnel exclusively in charge of computer systems management; however, results show that $39.5 \%$ do not have exclusive personnel for said department.

Regarding the application of Cloud Computing services in SMEs in the city of Latacunga, it were found that young companies of 5 years and those that range between 6 and 10 years choose to venture into the use of Cloud Computing with $32.1 \%$, while by sectors, it was detected that commerce makes more use of Cloud Computing with a percentage of $42.9 \%$. On the other hand, the remaining companies that do not contract the service say that it is because they have little or no knowledge about it, the cost of implementation, insecurity and dependence on a provider.

On the other hand, $65.1 \%$ of SMEs admit having heard the concept of Cloud Computing; however, $28.5 \%$ make use of Cloud Computing, $12.6 \%$ is assigned to IaaS as a more affordable model, $15.9 \%$ to PaaS and $0 \%$ to SaaS, the latter because although it seems to be more advantageous in use for companies, its limitation is the high economic implications of using the service.

In Figure 3, the frequency of use of cloud computing services is analyzed, where the repetition of the terms found is first associated with the size of the words and second with their location, the larger the term, and is located in the center, the greater its use. In this regard, the cloud services for SMEs in Latacunga stand out: office 365, abanq, sky drive, generated from an open question about CC.

Therefore, the relevant indexes were evaluated in terms of the advantages of the use of Cloud Computing, where: $86.1 \%$ thought they were saving infrastructure and personnel costs; $72.1 \%$ in portability when accessing information from anywhere in the world; $69.8 \%$ to the full availability of the service in relation to access without schedules and from any device and $67.4 \%$ to automatic storage of information.

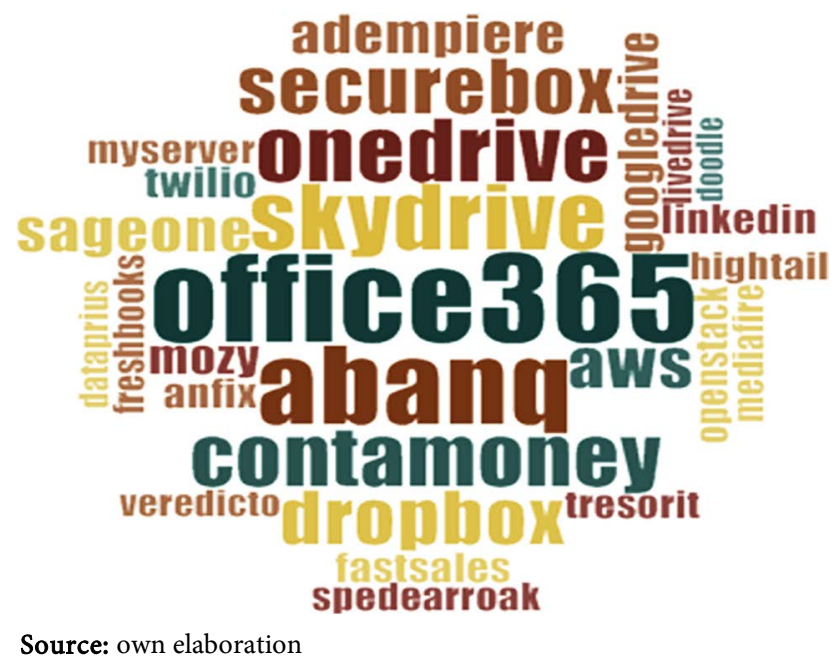

Figure 3. Frequency of use of cloud services. 
On the other hand, in the disadvantages section, confidentiality of information and security is one of the most relevant concerns with 76.7\%; the dependency of a provider with $72.1 \%$; as well as bandwidth problems with $68.9 \%$ due to the fact that, sometimes, this is suspended for some reason that causes delays in business activities.

In addition, the average investment made by companies in hiring the Cloud service was identified, where $27.9 \%$ indicate maintaining an investment percentage of more than 9001 dollars per year, followed by a percentage no greater than $14.0 \%$ in values of between 6001 and 9000 dollars, although the data that stands out the most is $48.8 \%$ of the respondents who prefer not to answer due to confidentiality issues.

Finally, to determine the level of maturity, an item was developed in a measurement scale of 5 points (not at all, not very, usually, almost and very mature), in which $39.5 \%$ answered that Cloud's level of maturity Computing is not mature, $32.6 \%$ that is in a range of usually mature, $20.9 \%$ said that it was not very mature and only $7.1 \%$ said that it could be said that it is almost mature. This suggests that Cloud's average maturity is approximately 25\%, which indicates that there has not yet been a Cloud acceptance level and therefore its adoption is very low.

\section{Hierarchical clusters}

The results of the exploratory analysis by classification of hierarchical clusters are shown in the following table of clusters of belonging:

The calculation made to form 2 to 4 groups (shown in Table 4) exposes the Table 4. Clusters of belonging.

\begin{tabular}{|c|c|c|c|}
\hline Variable & 4 clusters & 3 clusters & 2 clusters \\
\hline It has a main computer (exclusive server) & 1 & 1 & 1 \\
\hline Does your company use free software? & 2 & 2 & 1 \\
\hline User and password security & 1 & 1 & 1 \\
\hline Backup copies & 1 & 1 & 1 \\
\hline Security policies & 3 & 3 & 2 \\
\hline $\begin{array}{c}\text { On a regular basis, their workers receive ICT } \\
\text { management training }\end{array}$ & 2 & 2 & 1 \\
\hline $\begin{array}{c}\text { The company has staff dedicated exclusively to the area of } \\
\text { Information Systems, also known as the Department of } \\
\text { Information Technology (IT) }\end{array}$ & 1 & 1 & 1 \\
\hline Do you know the concept of Cloud Computing? & 1 & 1 & 1 \\
\hline SaaS (Software as a service) & 2 & 2 & 1 \\
\hline IaaS (Infrastructure as a service) & 4 & 2 & 1 \\
\hline PaaS (Platform as a service) & 1 & 1 & 1 \\
\hline The company hires a cloud service Cloud Computing & 1 & 1 & 1 \\
\hline
\end{tabular}

Source: own elaboration. 
variables that belong to each cluster or dimension, that is, the questions that most relate to each other have been grouped.

The groups allow to analyze the behavior of the different variables, which influence the decision of SMEs to use or not the Cloud Computing application are presented:

Cluster 1

- It has a main computer (exclusive server)

- User and password security

- Backups

- The company has personnel dedicated exclusively to the area of Information Systems, also known as the Department of Information Technology (IT)

- Do you know the concept of Cloud Computing?

- PaaS (Platform as a service)

- The company hires a cloud service Cloud Computing Cluster 2

- Does your company use free or free software?

- On a regular basis, their workers receive ICT management training

- SaaS (Software as a service)

The dendrogram, (Figure 4) is a graphic summary of the cluster solution, where the variables (items) are found along the left vertical axis. The horizontal axis shows the distance between the groups when they were joined (from 0 to

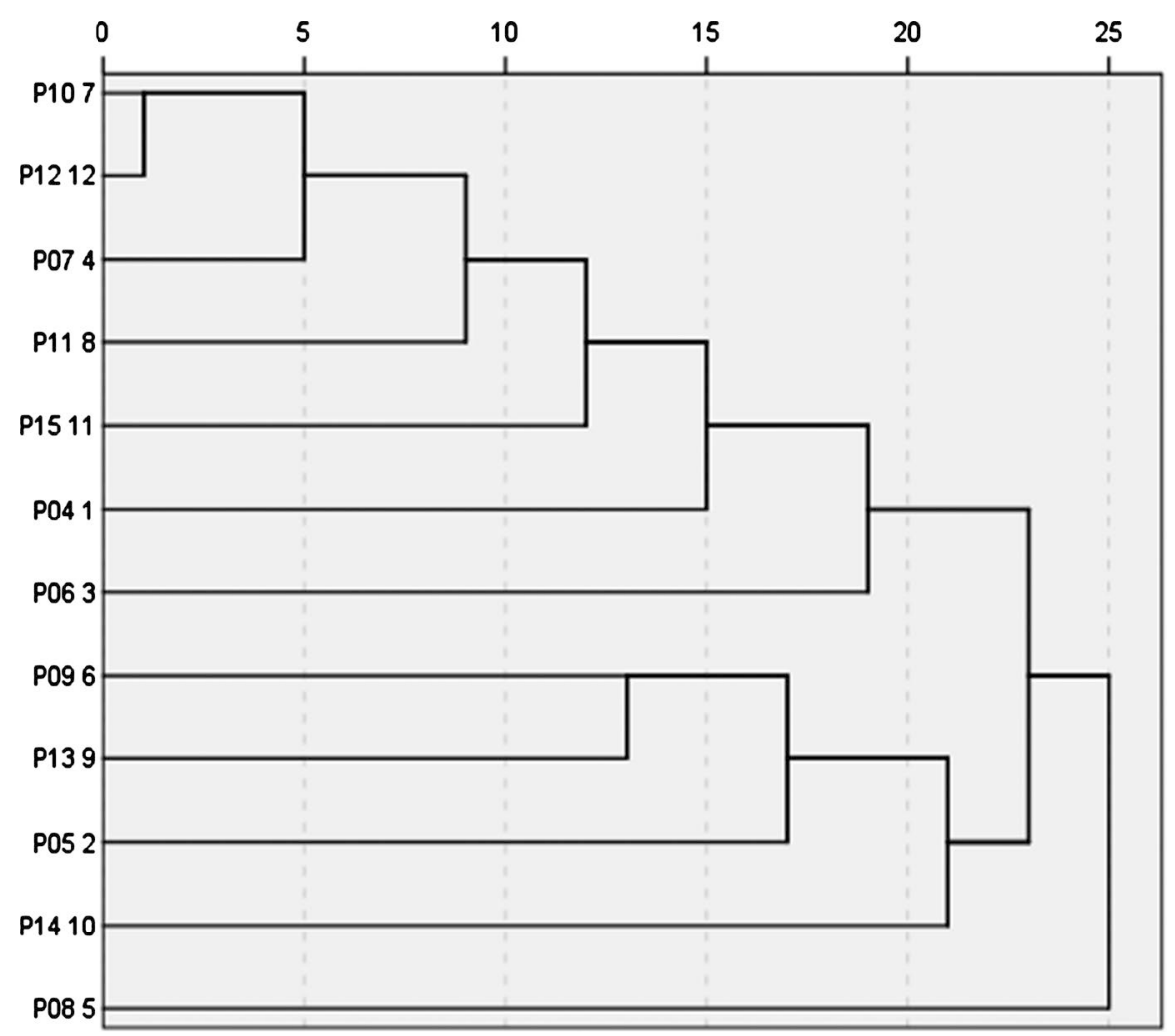

Source: own elaboration.

Figure 4. Combination of clusters of re-scaled distances. 
$25)$. The analysis of the classification tree to determine the number of groups, from right to left, with a gap that goes from 20 to 25 suggests two clusters: $(7,12$, $4,8,11,1,3)(3,6,9,2,10,5)$. Therefore, this figure shows how conglomerates are formed, which are groups of questions of greater similarity, for determining the use of CC in SMEs. In this way, two relevant groups are identified that analyze technological aspects, human talent in the area of ICT, security and their availability of resources, which influence the decision to adopt CC.

\section{Conclusions}

Once the main results have been presented relative to the analysis variables that define the usability of Cloud Computing in SMEs of the city of Latacunga, and by way of conclusion, it is determined that:

According to the bibliography found, SMEs play an important social role, both as a generator of employment and as a significant sector in national and international economies. In this context, the development of emerging technologies means that companies choose to acquire new technological services as a competitive advantage over their peers, which allows SMEs to reach a market segment in digital environments.

In this framework, the investigation of the current state of use of Cloud Computing in the SMEs of the city under study allowed to identify the factors that would promote or affect the hiring of this type of service. Among the disadvantages that stand out is security of the information. On the other hand, its main advantages are: cost savings in servers and permanent advice. The result of the diagnosis made is that young companies in the market choose this resource being the PaaS model the most used because they develop their own computerized systems, $65.1 \%$ admit having heard about the subject, $28.5 \%$ adopt this service in office automation applications, document repositories and in minimum amount contract SaaS, especially in the billing area. Companies that exceed 10 years remain indifferent to adopting this service.

\section{Conflicts of Interest}

The authors declare no conflicts of interest regarding the publication of this paper.

\section{References}

[1] Solano-Gallegos, S. (2018) The Importance of Small and Medium Enterprises in the City of Cuenca-Ecuador and Their Contribution to the Creation of Employment. Academy of Accounting and Financial Studies Journal, 22, 1-17.

[2] Coutinho, M.C. (2009) Ethics and Corporate Social Responsibility in Latin American Small and Medium Sized Enterprises: Challenging Development. African Journal of Business Ethics, 4, 37-47.

[3] Wisuttisak, P. (2017) Law for SMEs Promotion and Protection in Vietnam and Thailand. Review of Integrative Business and Economics Research, 6, 60-67.

[4] Odlin, D. (2019) Domestic Competitor Influence on Internationalizing SMEs as an 
Industry Evolves. Journal of World Business, 54, 119-136.

[5] Assis, M.R.M. and Bittencourt, L.F. (2016) A Survey on Cloud Federation Architectures: Identifying Functional and Non-Functional Properties. Journal of Network and Computer Applications, 72, 51-71. https://doi.org/10.1016/j.jnca.2016.06.014

[6] Ramachandra, G., Iftikhar, M. and Khan, F.A. (2017) A Comprehensive Survey on Security in Cloud Computing. Procedia Computer Science, 110, 465-472. https://doi.org/10.1016/j.procs.2017.06.124

[7] Ravi, K., Khandelwal, Y., Krishna, B.S. and Ravi, V. (2018) Analytics in/for Cloud-An Interdependence: A Review. Journal of Network and Computer Applications, 102, 17-37. https://doi.org/10.1016/j.jnca.2017.11.006

[8] Vafamehr, A. and Khodayar, M.E. (2018) Energy-Aware Cloud Computing. Electricity Journal, 31, 40-49. https://doi.org/10.1016/j.tej.2018.01.009

[9] Ratten, V. (2015) Continuance Use Intention of Cloud Computing : Innovativeness and Creativity Perspectives. Journal of Business Research, 69, 1737-1740.

[10] Bernal-Barcia, E.C. (2017) An Approach of the New Technology in the Different Sectors of Society. 3, 3-12.

[11] Trun, P. (2019) Infrastructures for High-Performance Computing: Cloud Computing. Encyclopedia of Bioinformatics and Computational Biology, 1, 236-239.

[12] Suárez, D. (2017) Flexibilidad Escalabilidad Almacenamiento. 26-43.

[13] Slusarczyk Antosz, M. (2015) Diagnosis of the ICT Aplication in the SMEs of Riobamba-Ecuador. 4, 145-168.

[14] Martínez-García, D., Medina-Chicaiza, P., Silva-Ordoñez, F., Mejía-Vayas, V. and Beltrán-Mesías, C. (2018) Diagnóstico del uso de la tecnología Cloud Computing en la administración de las empresas de servicios de la ciudad de Ambato. 1-21.

[15] López-Sevilla, G., Medina-Chicaiza, P., Freire-Aillón, T. and Fiallos-López, W. (2018) Characterization of Technologies "SAAS" as a Tool in Optimizing It Resources. Pulse, 2, 146-153.

[16] Hosseini, M. and Nord, T. (2018) A Combined Focused Industry and Company Size Investigation of the Internationalization-Performance Relationship: The Case of Small and Medium-Sized Enterprises (SMEs) within the Swedish Wood Manufacturing Industry. Forest Policy and Economics, 97, 110-121.

[17] Bagheri, M., Mitchelmore, S. and Bamiatzi, V. (2019) Internationalization Orientation in SMEs: The Mediating Role of Technological Innovation. Journal of International Management, 25, 121-139. https://doi.org/10.1016/j.intman.2018.08.002

[18] Chi, T. (2015) Business Contingency, Strategy Formation, and Firm Performance: An Empirical Study of Chinese Apparel SMEs. Administrative Sciences, 5, 27-45.

[19] Muñoz, M., Gasca, G. and Valtierra, C. (2014) Caracterizando las Necesidades de las Pymes para Implementar Mejoras de Procesos Software: Una Comparativa entre la Teoría y la Realidad. RISTI, 1-15.

[20] Tovar, C. (2017) Investigación sobre la aplicación de business research on business intelligence application in the argentine SMEs Management. Palermo Business Review, No. 15, 79-98.

[21] Sánchez-Val, M.M. and Llorens, M.C.R. (2016) La incidencia de los entornos regionales sobre las restricciones financieras en pequeñas y medianas empresas. Trimestre Economico, 83, 37-60. https://doi.org/10.20430/ete.v83i329.191

[22] J Garcia-Noboa, J.P., Castillo-Torres, L.B. and Torres-Miranda, J.E. (2017) Retos y Perspectivas del Desarrollo Económico en el Ecuador y América Latina. Centro de Investigación y Desarrollo Ecuador, 1, 51-66. 
[23] CAN. (2009) Año XXVI-Número 1743 Lima, 24 de agosto de 2009 Secretaría General de la Comunidad Andina Resolución 1259 Disposición Técnica para la Transmisión de Datos de Estadísticas Coyunturales de la Industria Manufacturera de los Países Miembros de la Comunidad. 1-116.

[24] Campuzano Rodriguez, M.A., Ziadet Bermùdez, E.I. and Echeverria Vasque, H.G. (2016) Gestión del Talento Humano en las PYMES. Revista Publicando, 3, 438-448. https://revistapublicando.org/revista/index.php/crv/article/view/272/pdf-145

[25] Daneshgar, F., Low, G.C. and Worasinchai, L. (2013) An Investigation of "Build vs. Buy" Decision for Software Acquisition by Small to Medium Enterprises. Information and Software Technology, 55, 1741-1750.

[26] Guercio, M.B., Martinez, L.B. and Vigier, H. (2017) Las limitaciones al financiamiento bancario de las Pymes de alta tecnología. Estudios Gerenciales, 33, 3-12.

https://doi.org/10.1016/j.estger.2017.02.001

[27] Platero-Jaime, M., Benito-Hernández, S. and Rodríguez-Duarte, A. (2017) The Moderator Effect of Training in the Adoption of ICT in Microenterprises. Cuadernos de Gestion, 17, 87-108. https://doi.org/10.5295/cdg.150539mp

[28] Ministerio de Telecomunicaciones y de la Sociedad de Información (2016) Plan Nacional de Telecomunicaciones y Tecnologías de Información del Ecuador. Journal of Experimental Psychology: General, 1-66.

[29] Consejo Nacional de Planificacón (2013) Plan Nacional del Buen Vivir (Global Network). 1-133.

[30] INEC (2015) Empresas y TIC (Tecnologías de la Información y la Comunicación). Inec, 54.

[31] Herrera, A. and Janczewski, L. (2014) Issues in the Study of Organisational Resilience in Cloud Computing Environments. Procedia Technology, 16, 32-41. https://doi.org/10.1016/j.protcy.2014.10.065

[32] Oliveira, T., Thomas, M. and Espadanal, M. (2014) Assessing the Determinants of Cloud Computing Adoption: An Analysis of the Manufacturing and Services Sectors. Information and Management, 51, 497-510.

https://doi.org/10.1016/j.im.2014.03.006

[33] Priyadarshinee, P., Raut, R.D., Kumar, M. and Kamble, S.S. (2017) A Cloud Computing Adoption in Indian SMEs: Scale Development and Validation Approach. The Journal of High Technology Management Research, 28, 221-245.

[34] Al-samarraie, H. and Saeed, N. (2018) A Systematic Review of Cloud Computing Tools for Collaborative Learning: Opportunities and Challenges to the BlendedLearning Environment. Computers and Education, 124, 77-91.

https://doi.org/10.1016/j.compedu.2018.05.016

[35] Cayirci, E. and de Oliveira, A.S. (2018) Modelling Trust and Risk for Cloud Services. Journal of Cloud Computing, 7, Article No. 114. https://doi.org/10.1186/s13677-018-0114-7

[36] Indu, I., Anand, P.M.R. and Bhaskar, V. (2018) Identity and Access Management in Cloud Environment: Mechanisms and Challenges. Engineering Science and Technology, 21, 574-588. https://doi.org/10.1016/j.jestch.2018.05.010

[37] Ali, M., Khan, S.U. and Vasilakos, A.V. (2015) Security in Cloud Computing: Opportunities and Challenges. Information Sciences, 305, 357-383. https://doi.org/10.1016/j.ins.2015.01.025

[38] Souri, A., Navimipour, N.J. and Rahmani, A.M. (2018) Formal Verification Approaches and Standards in the Cloud Computing: A Comprehensive and Systematic 
Review. Computer Standards and Interfaces, 58, 1-22.

[39] Rocha, L., Gomez, A., Araújo, N., Otero, C. and Rodrigues, D. (2016) Cloud Management Tools for Sustainable SMEs. Procedia CIRP, 40, 220-224.

https://doi.org/10.1016/j.procir.2016.01.106

[40] Aslam, S., ul Islam, S., Khan, A., Ahmed, M., Akhundzada, A. and Khan, M.K. (2017) Information Collection Centric Techniques for Cloud Resource Management: Taxonomy, Analysis and Challenges. Journal of Network and Computer Applications, 100, 80-94. https://doi.org/10.1016/j.jnca.2017.10.021

[41] Abdel-Basset, M., Mohamed, M. and Chang, V. (2018) NMCDA: A Framework for Evaluating Cloud Computing Services. Future Generation Computer Systems, 86, 12-29. https://doi.org/10.1016/j.future.2018.03.014

[42] Aznoli, F. and Navimipour, N.J. (2017) Cloud Services Recommendation: Reviewing the Recent Advances and Suggesting the Future Research Directions. Journal of Network and Computer Applications, 77, 73-86. https://doi.org/10.1016/j.jnca.2016.10.009

[43] Bogataj Habjan, K. and Pucihar, A. (2017) The Importance of Business Model Factors for Cloud Computing Adoption: Role of Previous Experiences. Organizacija, 50, 255-272. https://doi.org/10.1515/orga-2017-0013

[44] Noor, T.H., Zeadally, S., Alfazi, A. and Sheng, Q.Z. (2018) Mobile Cloud Computing: Challenges and Future Research Directions. Journal of Network and Computer Applications, 115, 70-85. https://doi.org/10.1016/j.jnca.2018.04.018

[45] Tan, C.B., Hijazi, M.H.A., Lim, Y. and Gani, A. (2018) A Survey on Proof of Retrievability for Cloud Data Integrity and Availability: Cloud Storage State-of-the-Art, Issues, Solutions and Future Trends. Journal of Network and Computer Applications, 110, 75-86.

[46] Jafarnejad Ghomi, E., Masoud Rahmani, A. and Nasih Qader, N. (2017) Load-Balancing Algorithms in Cloud Computing: A Survey. Journal of Network and Computer Applications, 88, 50-71. https://doi.org/10.1016/j.jnca.2017.04.007

[47] Vasiljeva, T., Shaikhulina, S. and Kreslins, K. (2017) Cloud Computing: Business Perspectives, Benefits and Challenges for Small and Medium Enterprises (Case of Latvia). Procedia Engineering, 178, 443-451. https://doi.org/10.1016/j.proeng.2017.01.087

[48] Galdino-Evangelista, W. and Souza-Neto, J. (2016) Modelo de avaliação da capacidade das organizações da administração pública federal para a adoção de software as a service (SaaS) público. Revista Do Serviço Público, 67, 173-202.

[49] Iglesias, A. (2017) El “cloud” en españa se hace mayor de edad.

[50] Lazo Villela, S. (2012) Factores relevantes que inciden en la adopción de la Computación en Nube en las Universidades de Puerto Rico, 129.

[51] Henao-Diaz, L.F., Pacheco-Fernández, N.M., Argüello-Bernal, S., Moreno-Arocha, M.M. and Stevenson, P.R. (2012) Patrones De Diversidad De Epífitas En Bosques De Tierras Bajas Y Subandinos. Colombia Forestal, 15, 161-172. http://revistas.udistrital.edu.co/ojs/index.php/colfor/article/view/3758/5617 https://doi.org/10.14483/udistrital.jour.colomb.for.2012.2.a02

[52] MINTEL (2018) Libro blanco de la Sociedad de la Información y del Conocimiento. Telecomunicaciones. Gob. Ec, 1, 1-155.

[53] Kestin, I. (2018) Statistics in Clinical Trials and Audit. Anaesthesia and Intensive Care Medicine, 19, 144-148. https://doi.org/10.1016/j.mpaic.2017.12.004

[54] Leppink, J. (2017) Helping Medical Students in their Study of Statistics: A Flexible 
Approach. Journal of Taibah University Medical Sciences, 12, 1-7. https://doi.org/10.1016/j.jtumed.2016.08.007

[55] Budgen, D., Brereton, P., Williams, N. and Drummond, S. (2018) The Contribution that Empirical Studies Performed in Industry Make to the Findings of Systematic Reviews: A Tertiary Study. Information and Software Technology, 94, 234-244. https://doi.org/10.1016/j.infsof.2017.10.012

[56] Fernández-Sáez, A.M., Genero, M. and Chaudron, M.R.V. (2013) Empirical Studies Concerning the Maintenance of UML Diagrams and Their Use in the Maintenance of Code: A Systematic Mapping Study. Information and Software Technology, 55, 1119-1142. https://doi.org/10.1016/j.infsof.2012.12.006

[57] Boongoen, T. and Iam-on, N. (2018) Cluster Ensembles: A Survey of Approaches with Recent Extensions and Applications. Computer Science Review, 28, 1-25. https://doi.org/10.1016/j.cosrev.2018.01.003

[58] Peña, M. (2018) Robust Clustering Methodology for Multi-Frequency Acoustic Data: A Review of Standardization, Initialization and Cluster Geometry. Fisheries Research, 200, 49-60.

[59] Sardar, T.H. and Ansari, Z. (2018) Partition Based Clustering of Large Datasets Using MapReduce Framework: An Analysis of Recent Themes and Directions. Future Computing and Informatics Journal, 3, 247-261.

https://doi.org/10.1016/j.fcij.2018.06.002 